Research Article

\title{
Experimental Study on an Innovative Hollow Concrete Floor System Assembled with Precast Panels and Self-Thermal-Insulation Infills
}

\author{
Liang Gong $\mathbb{D}^{1,2}$ Zhongfan Chen $\mathbb{D}^{1,},{ }^{1,2}$ Yan Feng $\mathbb{D}^{\mathbb{D}},{ }^{1,2}$ Sihan Ruan, ${ }^{1,2}$ and Liuhui Tu ${ }^{1,2}$ \\ ${ }^{1}$ Key Laboratory of RC\&PC Structures of Ministry of Education, Southeast University, Nanjing 210096, China \\ ${ }^{2}$ School of Civil Engineering, Southeast University, Nanjing 210096, China \\ Correspondence should be addressed to Zhongfan Chen; 101003944@seu.edu.cn
}

Received 18 November 2020; Accepted 12 July 2021; Published 27 July 2021

Academic Editor: Michael Yam

Copyright (c) 2021 Liang Gong et al. This is an open access article distributed under the Creative Commons Attribution License, which permits unrestricted use, distribution, and reproduction in any medium, provided the original work is properly cited.

This paper presents an innovative hollow concrete floor system comprising hollow precast panels and self-thermal-insulation infills. The precast panels are connected by welded reinforcement bars and cast-in-situ concrete joints. To study the vertical loadcarrying capacity and the working mechanism of this innovative floor system, a static loading test was carried out on a $1 / 2$ scale model. The specimen consists of six precast slab members, four precast reinforced concrete beams and columns, respectively. Experimental and simulation results related to the crack development and vertical load-carrying capacity were analyzed. It is found that the innovative floor system could meet the capacity requirements of the Chinese code. Furthermore, the crack development of the innovative system shows similar characteristics with the solid floor. To explore the feasibility of the existed analysis methods, the specimen was simulated and compared by nonlinear analysis in ABAQUS. The comparison illustrates that the analogue cross beam method is more accurate and suitable for the simulation of the innovative hollow concrete floor system.

\section{Introduction}

As a reliable construction building material, concrete could meet the requirements of demanding construction conditions, different shaped structural components, and harsh environment for its mature construction technologies and superior properties [1-3]. With the increasing industrialization and commercialization of civil engineering, the requirements of buildings have converted to large-span structures, which present new challenges to the concrete floor system [4-6].

To eliminate the inherent limits of the traditional concrete floor system and extend its use in modern structures, researchers all over the world have conceived different kinds of effective solutions. The innovations mainly focused on new patterns of floor systems [7].

In the 1960s, Mueller invented the B-Z reinforced concrete cellular plate [8], which is a kind of cast-in-situ concrete hollow slab. Experimental research on this new type of floor was carried out by Franz [9] and the results showed that the stiffness of the hollow floor was equivalent to the solid flat slab. Hendler [10] improved the floor system by inserting a block of foamed plastic in the cavity of the hollow slab. Influential factors, such as the height of the slab, compressive strength of the concrete, and the patterns of the joint, were all carefully investigated. The corresponding calculation methods to estimate the load-carrying capacity and initial stiffness were proposed [11].

In recent decades, the precast concrete structures have become a preferable choice for their prominent advantages, i.e., high efficiency, standardization, and environmental friendliness [12]. In China, several innovative floor systems were also developed to exploit the highest efficiency of precast panels and to meet the requirements of large-span structures [13]. Ma proposed a Vierendeel-sandwich-plate floor system [14], which is comprised of two layers of ribbed reinforced concrete slab connected by reinforced concrete shear keys at the intersection. Through the design and 
construction of a real-life project, the feasibility of this new floor system was verified. Other kinds of novel floor systems, i.e., PK prestressed composite slab floor system [15], the assembled monolithic hollow-ribbed floor [16], prefabricated PC floor system [17], and other new systems [18-22], were all investigated, and the results were satisfactory.

This paper presents a new type of floor system, which consists of hollow precast panels, self-thermal-insulation infills, joints with welded reinforcement, and cast-in-situ concrete beams. The hollow panels were prefabricated in the manufacturing factory with two different patterns (Figure 1), which can meet various requirements in actual construction. The self-thermal-insulation infill, i.e., the foam concrete, was inserted in the cavity of the hollow concrete panels to enhance the thermal insulation properties and vertical stiffness at the same time. The precast concrete panels were connected with the cast-in-place joint and welded reinforcements for larger span buildings, as shown in Figure 2. This type of floor system is of the advantages in both mechanical performance and manufacturing efficiency, such as (1) reduced self-weight: the light-weighted foam concrete accounts for $48 \%$ of the total volume of the floor, thus it is $44.7 \%$ lighter than the same sized solid floor; (2) enhanced floor height: there will be spare room since the bottom plate is flat, and the pipeline can be arranged in the middle of the plate as the equipment layer; (3) superior sound and thermal insulation: the filled lightweight foamed concrete improves the sound and thermal insulation of the floor; (4) high construction efficiency: the prefabrication degree reaches $87.5 \%$, which accelerates the construction speed enormously.

To study the working mechanism of the innovative floor system and verify its effectiveness, a 1/2 scale single-span simply supported floor was tested through a static load experiment. The results related to the crack development, initial stiffness, and vertical load-carrying capacity were analyzed.

\section{Experimental Investigation}

2.1. Material Properties. The steel rods used in the precast and cast-in-place components are HRB 400, according to GB 50010-2010 [23]. The diameter of the steel bars encompasses four different sizes, i.e., $16 \mathrm{~mm}, 10 \mathrm{~mm}, 8 \mathrm{~mm}$, and $3.5 \mathrm{~mm}$. Mechanical properties of the steel bars were tested by the test method of GB/T 228.1-2010 [24]. Results are collected in Table 1.

The concrete is C30 in the columns and beams and C40 in the cast-in-situ joint and the slab, according to GB 500102010. Compressive and tensile tests were all performed on the standard cubic specimens sized $150 \mathrm{~mm}$. The material properties are presented in Table 2.

2.2. The Similarity Ratio. Due to the limitation of the test platform, the test specimen was designed in a $1 / 2$ scale. The component's size, load, and additional mass are designed in strict accordance with the similarity theory to ensure the model and the prototype share similar working conditions. For scale models, the relationship between the elastic modulus, density, geometry sizes, and gravitational acceleration is presented as follows:

$$
\frac{S_{E}}{\left(S_{g} S_{p}\right)}=S_{l},
$$

where $S_{E}$ is the similarity constant of elastic modulus, $S_{g}$ is the similarity constant of gravity acceleration, $S_{\rho}$ is the similarity constant of material density, and $S_{l}$ is the similarity ratio of geometric size.

The material used in the scaled model is identical to those of the prototype; thus, the similarity constant related to material properties is equal to 1 . Based on the similarity constant of geometry and material, $S_{\rho}$ can be calculated as 2 . It is impossible to adjust the density without changing its volume for a specific material. To meet the material similarities of both density and mechanics, additional weights were added to the model. Other similarity relationships are all calculated and presented in Table 3.

2.3. Specimen Preparation. A one-storey frame was designed to explore the vertical load-carrying capacity and working mechanism of the innovative hollow concrete floor system. The specimen is presented in Figure 3, comprised of three different components, i.e., the beams, columns, and the innovated hollow slab. The cross section of the four columns is $300 \mathrm{~mm} \times 300 \mathrm{~mm}$, which is designed according to the axial compression ratio in the GB 50011-2010 [25]. The ratio of reinforcement and selection of steel bars (Figure 3) was identical to both the prototype and the requirements in GB 50011-2010. Four beams of $200 \mathrm{~mm} \times 350 \mathrm{~mm} \times 4800 \mathrm{~mm}$ were employed to support the floor. Similar to the columns, the reinforcement and size conform to meet a criterion up to the standards.

The location of the cast-in-situ joints was designed according to the original building. There were three post-cast concrete joints in the floor system, including two transverse joints and one longitudinal joint. The longitudinal joint was located in the middle of the span, and the transverse joint was located at $1 / 3$ and $2 / 3$ of the span. The width of the joint was determined to be $200 \mathrm{~mm}$ according to the length of the reinforcement connection. Every two adjacent precast panels were connected through welded reinforcement and cast-in-situ concrete joint, as presented in Figure 4. The reinforcement bars were evenly distributed in the concrete joint with a diameter of $8 \mathrm{~mm}$ and an average distance of $75 \mathrm{~mm}$, respectively.

The floor system in Figure 5 needs to bear the required area load with limited deflection and crack according to GB 50010-2010, on which static load experiment was conducted.

Before the test, white paint and grids were painted on the bottom surface of the floor to determine the cracking position, and the grid spacing shall be $200 \mathrm{~mm}$. The protective scaffolds were located $100 \mathrm{~mm}$ below the bottom of the slab for protection without restricting the free deformation of the floor. 

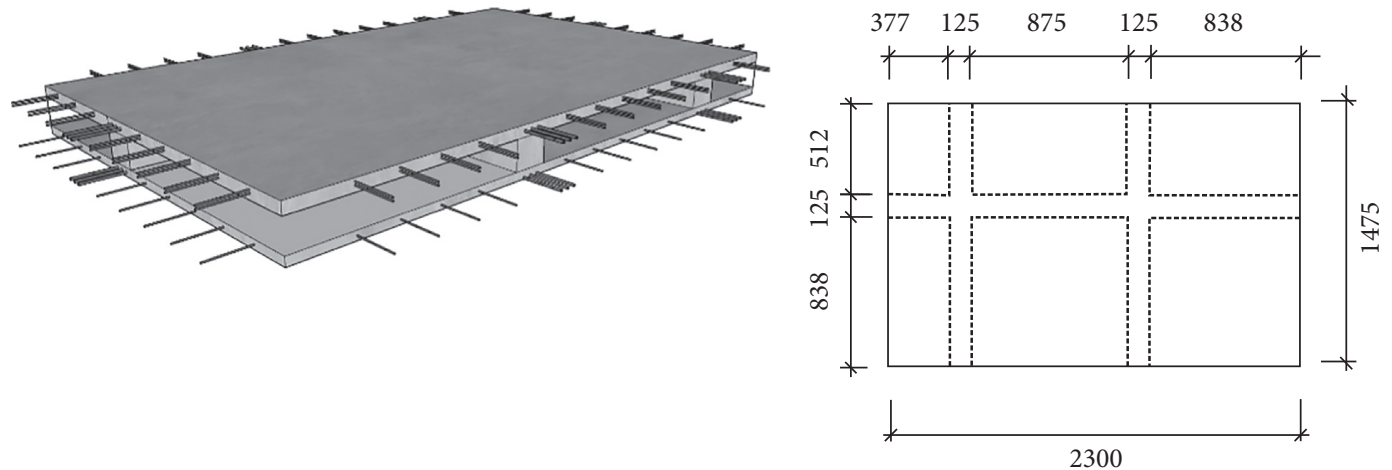

(a)

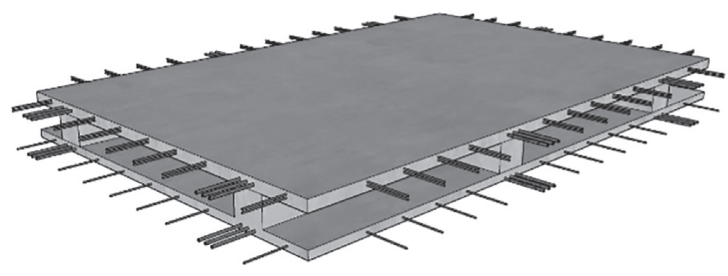

(c)

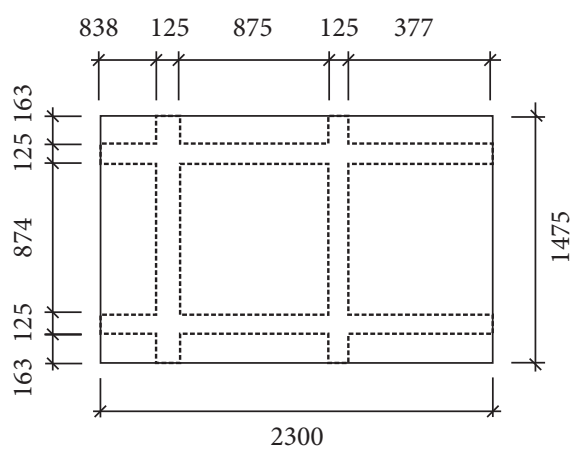

(d)

FIgure 1: Precast hollow concrete panels: (a) type I; (b) details of type-I panel; (c) type II; (d) details of type-II panel (unit: mm).

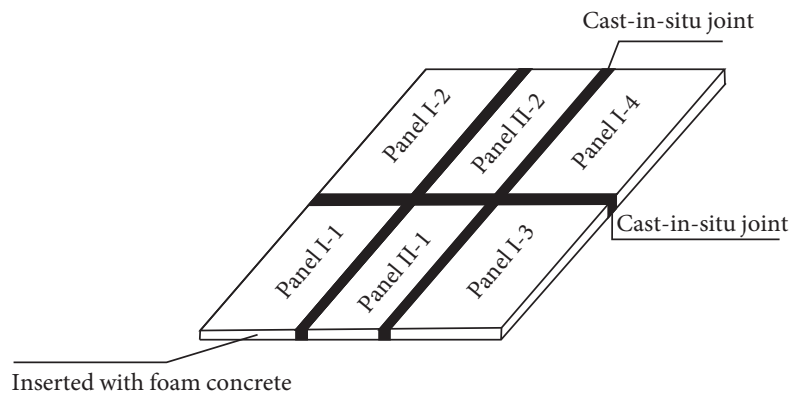

FIgURE 2: Innovated hollow composite concrete floor system assembled with precast panels and self-thermal-insulation infills.

TABLE 1: Material properties of steel bars.

\begin{tabular}{|c|c|c|c|c|}
\hline Tensile strength & Diameter $(\mathrm{mm})$ & Yield strength $(\mathrm{MPa})$ & Young's modulus (GPa) & Passion ratio \\
\hline Longitudinal bar in beams and columns & 16 & 386.7 & 211.19 & 0.28 \\
\hline Stirrup in beams and columns & 10 & 394.1 & 209.53 & 0.28 \\
\hline Longitudinal bar in ribbed beams & 8 & 390.1 & 209.31 & 0.28 \\
\hline Stirrup in ribbed beams & 8 & 390.1 & 210.03 & 0.28 \\
\hline Longitudinal bar in slab & 3.5 & 306.2 & 210.57 & 0.28 \\
\hline
\end{tabular}

TABLE 2: Material properties of concrete.

Position of the concrete Compressive strength, $f_{c u}(\mathrm{MPa})$ Elastic modulus, $E_{c}(\mathrm{MPa})$

Concrete in beams and columns

28.5


TABLE 3: Similarity constant of the specimen.

\begin{tabular}{|c|c|c|c|}
\hline & Parameter & Dimension & Similarity relationship \\
\hline \multirow{4}{*}{ Material properties } & Strain, $\sigma$ & $\mathrm{FL}^{-2}$ & $S_{E}=S_{\sigma}=1$ \\
\hline & Stress, $\varepsilon$ & - & 1 \\
\hline & Elastic modulus, $E$ & $\mathrm{FL}^{-2}$ & $S_{E}=1$ \\
\hline & Passion's ratio, $v$ & - & 1 \\
\hline \multirow{5}{*}{ Geometry } & Length, $l$ & $\mathrm{~L}$ & $S_{l}=1 / 2$ \\
\hline & Displacement, $\chi$ & $\mathrm{L}$ & $S_{\chi}=S_{l}=1 / 2$ \\
\hline & Angular displacement, $\theta$ & - & 1 \\
\hline & Area, $A$ & $L^{2}$ & $S_{A}=S_{l}^{2}=1 / 4$ \\
\hline & Moment of inertia, $I$ & $L^{4}$ & $S_{I}=S_{l}^{4}=1 / 16$ \\
\hline \multirow{4}{*}{ Load } & Concentrated load, $P$ & $\mathrm{~F}$ & $S_{p}=S_{E} S_{l}^{2}=1 / 4$ \\
\hline & Line load, $\omega$ & $\mathrm{FL}^{-1}$ & $S_{\omega}=S_{E} S_{l}=1 / 2$ \\
\hline & Area load, $q$ & $\mathrm{FL}^{-2}$ & $S_{q}=S_{E}=1$ \\
\hline & Moment, $M$ & FL & $S_{M}=S_{E} S_{l}^{3}=1 / 8$ \\
\hline
\end{tabular}

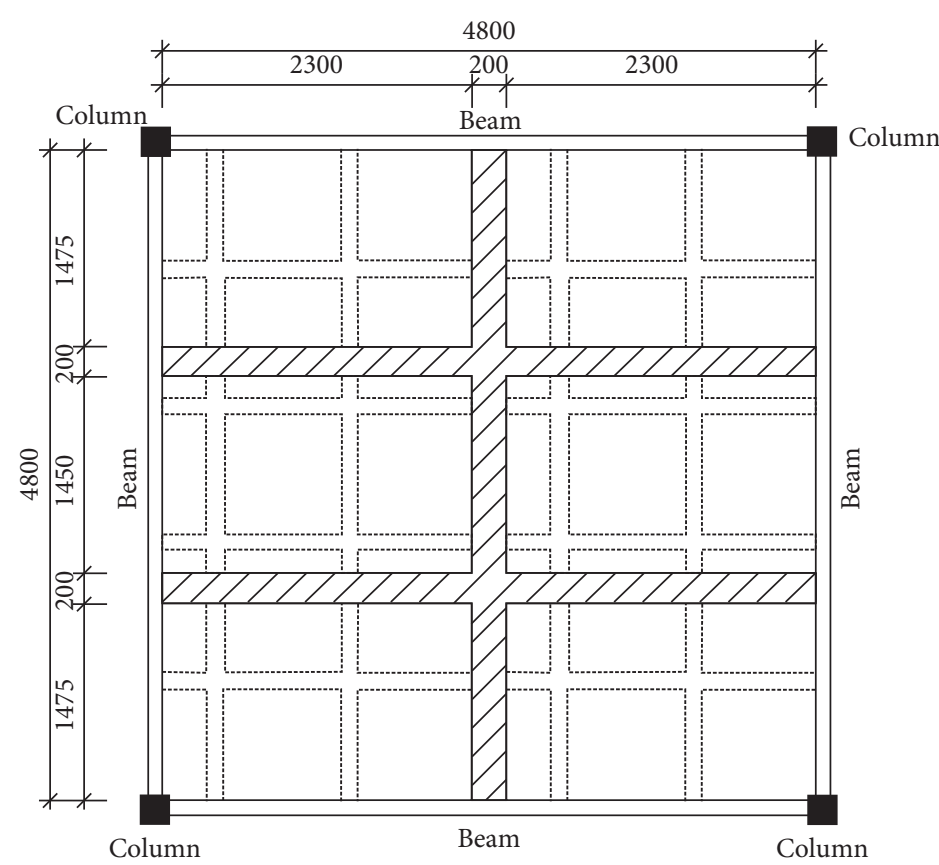

(a)

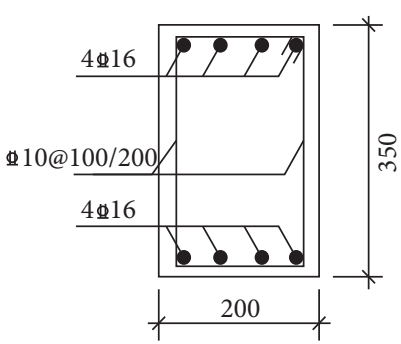

(b)

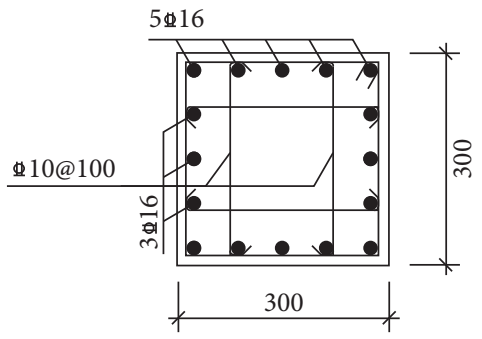

(c)

FiguRE 3: Detailed sizes of the innovated floor specimen: (a) schematic picture of the floor system; (b) beam; (c) column.

2.4. Load Protocol. Table 3 shows that the similarity ratio of stress and strain is equal to 1 , indicating that the stain and stress got from the $1 / 2$ scale are identical to those of the prototype. The area load could be directly calculated since $S_{q}=1$.
Mass bags were used to exert a uniformly distributed area load on the floor (see Figure 6). The transverse and longitudinal gap between each stack of sandbags was $10 \mathrm{~cm}$, larger than the requirements of GB/T50152-2012 [26] to avoid the arch effect after the deformation of the specimen. 


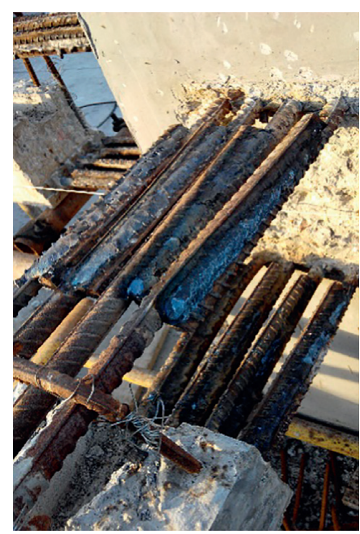

(a)

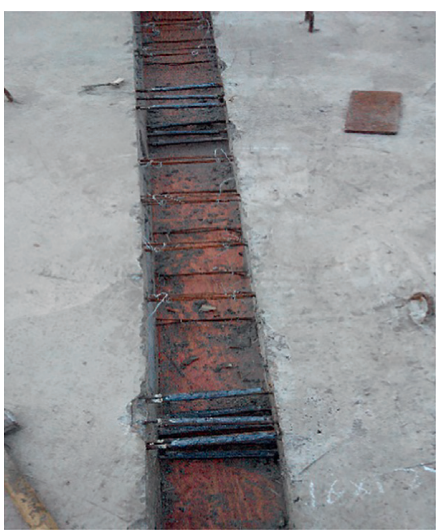

(b)

Figure 4: The joint between two adjacent precast panels. (a) Welded steel bars. (b) Cast-in-situ concrete beam.

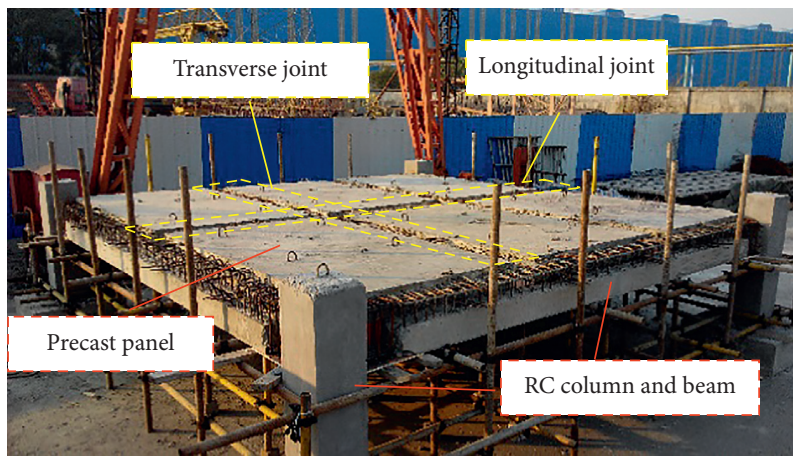

FIGURE 5: Tested specimen.

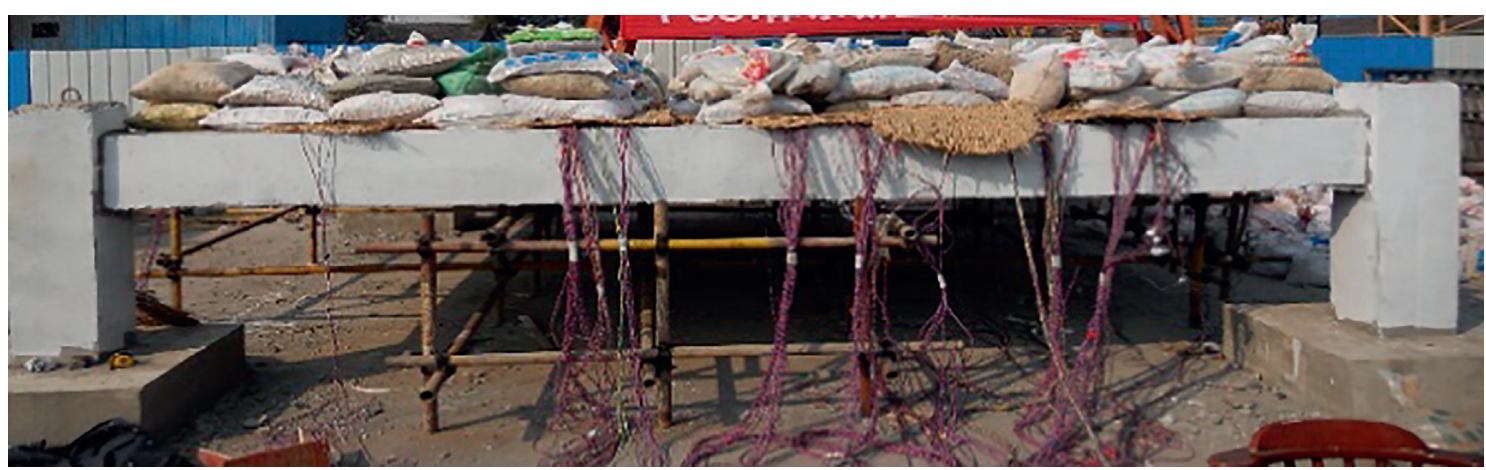

Figure 6: Area load exerted of the slab.

Three loading steps are included in the experiment, i.e., preloading, static loading, and unloading. Before the start of the static loading, preloading was conducted to check the stability of the structural support and eliminate the malfunctions of instruments and equipment. The static loading is designed according to the test methods of GB/T501522012 with ten main steps. After each stage of loading, the load was maintained for 15-20 minutes. The data collection and crack description were carried out after the structural deformation became stable. After the test, the mass bags on the floor were removed in batch, and the cracking of the concrete on the bottom surface of the floor could be observed after complete unloading.
The loading protocol is presented in Table 4 .

2.5. Sensor Distribution. Three types of sensors, i.e., the displacement transducer, the strain gauges, and the crack width observation instruments, were used during the test. The deformation of the slab was monitored with displacement transducers arranged as Figure 7. Due to the symmetry of the structure, the displacement meters were distributed on the $1 / 4$ side of the floor area.

The strain of steel bars was recorded with $2 \mathrm{~mm} \times 1 \mathrm{~mm}$ strain gauges. The layout of strain gauges mainly focused on the comparison of strain along the ribbed beam at different 
TABLE 4: Load protocol of the experiment.

\begin{tabular}{lccc}
\hline Load grade no. & Area load $\left(\mathrm{kN} / \mathrm{m}^{2}\right)$ & Accumulated area load $\left(\mathrm{kN} / \mathrm{m}^{2}\right)(\mathrm{MPa})$ & Last time $(\mathrm{min})$ \\
\hline 0 & 2.66 & 2.66 & - \\
1 & 0.94 & 3.6 & $15-20$ \\
2 & 0.94 & 4.54 & $15-20$ \\
3 & 0.78 & 5.32 & 960 \\
4 & 0.94 & 6.26 & $15-20$ \\
5 & 0.94 & 7.20 & 120 \\
6 & 0.94 & 8.14 & $15-20$ \\
7 & 0.94 & 9.08 & $15-20$ \\
8 & 0.94 & 10.02 & $15-20$ \\
9 & 0.94 & 10.96 & $15-20$ \\
10 & 0.94 & 11.9 & $15-20$ \\
11 & 0.94 & 12.84 & $15-20$ \\
\hline
\end{tabular}

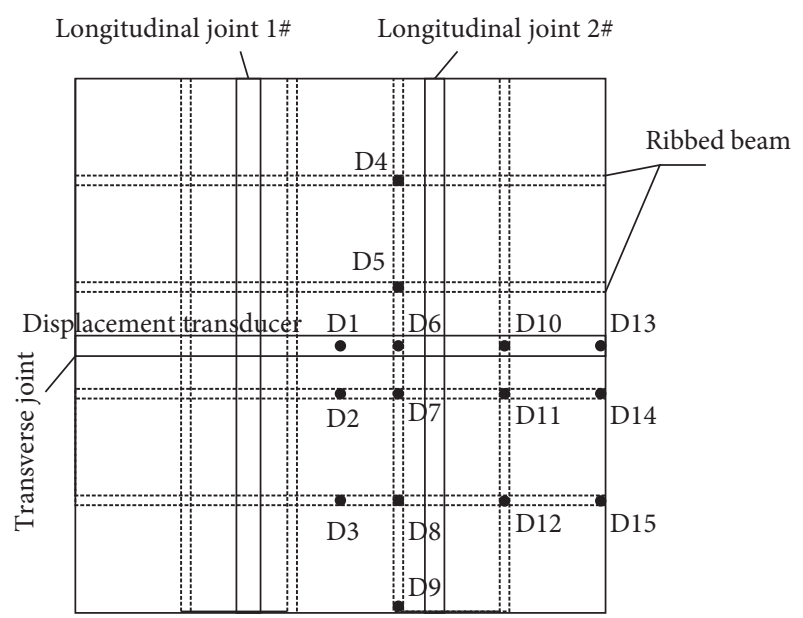

FIGURE 7: Arrangement of displacement transducers on the bottom surface.

positions and their differences with the others, as presented in Figure 8. The gauges were fixed on the steel bar before the cast of concrete. Glue and bandage were applied to the gauge and the outer layer of the conductor to avoid damage during concrete pouring.

To explore the stress development of the floor under different loads for later theoretical and numerical analysis, concrete strain gauges $(8 \mathrm{~mm} \times 2 \mathrm{~mm})$ were arranged on the top and bottom surface of the floor. Figure 9 illustrates the layout of strain gauges on the concrete slab.

\section{Experimental Results}

3.1. Experimental Observation. The deflection and crack development were monitored and logged while loading, which can be concluded as follows.

At the initial loading stages, the deflection in the middle of the slab increased with the load. No cracks were found at other parts of the slab bottom except for some shrink fractures. When the load reached $6.26 \mathrm{kN} / \mathrm{m}^{2}$ (the $4^{\text {th }}$ load), a small number of tiny cracks parallel to the direction of the joint appeared on the interface between the new and old concrete. The cracks mainly appeared in the middle of the joint.

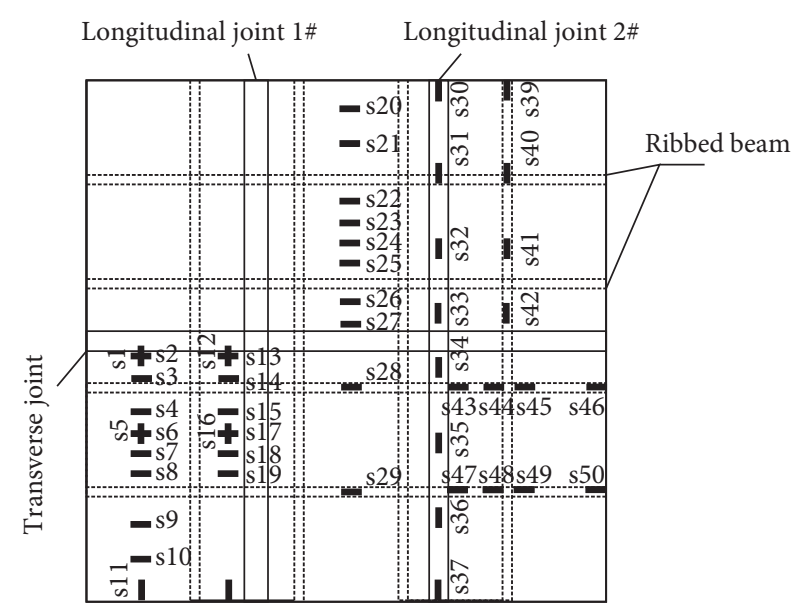

Figure 8: Layout of the strain gauges on steel bars.

With the accumulated load increasing from $6.26 \mathrm{kN} / \mathrm{m}^{2}$ to $8.14 \mathrm{kN} / \mathrm{m}^{2}$, the cracks parallel to the longitudinal interface of the joint furtherly developed and extended to the transverse direction. The interfaces between the new and old concrete of the longitudinal joint cracked, and the maximum width was about $0.2 \mathrm{~mm}$.

When the $7_{\text {th }}$ area load reached $9.08 \mathrm{kN} / \mathrm{m}^{2}$, almost all the surfaces of the joints cracked and slight cracks appeared at the bottom of the grid plate near the middle of the span. There were no cracks on the floor at the non-joint position. And the area load is slightly greater than the normal use load, which is $8.5 \mathrm{kN} / \mathrm{m}^{2}$ according to GB 50009-2012. Thus, the maximum crack met the requirements of normal use.

After the area load of the slab reached $10.02 \mathrm{kN} / \mathrm{m}^{2}\left(8_{\text {th }}\right.$ load), the cracks on the precast slab occurred. Most of the cracks were located near the diagonal line and no cracks were found at the bottom of the rib beam. When the load increased to $10.96 \mathrm{kN} / \mathrm{m}^{2}$ (9 $9_{\text {th }}$ load), several diagonal cracks developed in the middle of the floor and passed through the bottom of the rib beam. When the load reached $11.9-12.84 \mathrm{kN} / \mathrm{m}^{2}$, a large number of cracks appeared in the middle of the span. The width of one crack increased to approximately $1.5 \mathrm{~mm}$, which forced the loading process to stop due to security reasons.

The load in the experiment was greater than the requirements of both normal use and ultimate loading capacity according to GB 50009-2012, which verified the 


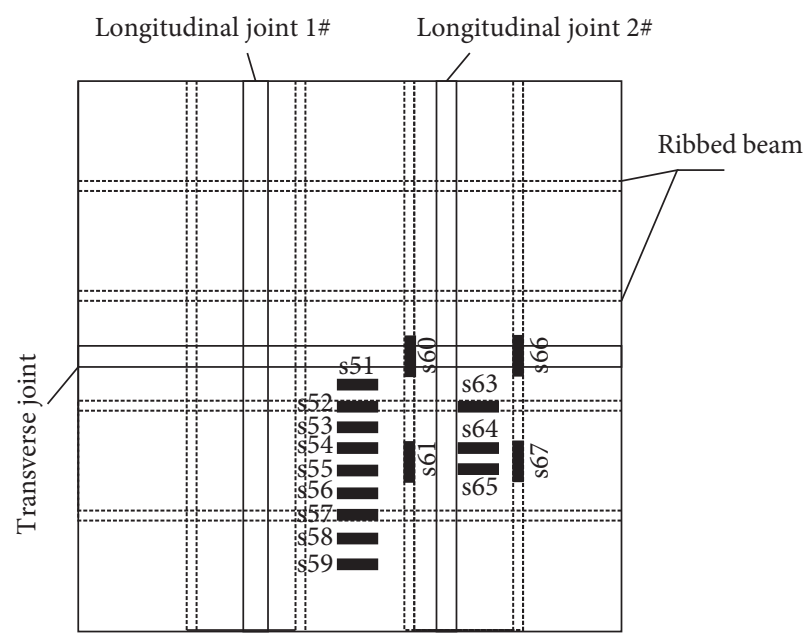

(a)

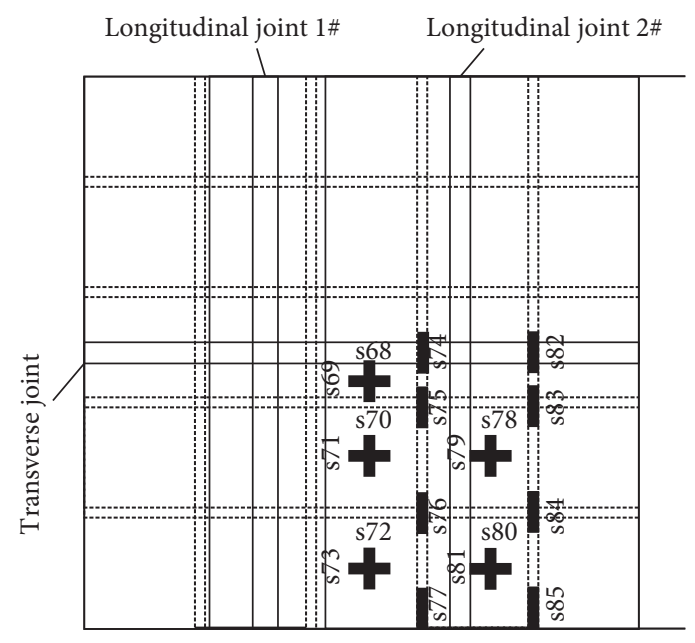

(b)

Figure 9: Layout of the strain gauges on concrete slab: (a) top surface; (b) bottom surface.

effectiveness and practicability of this innovative floor system. It can be observed that the main crack of the concrete is X-shaped (Figure 10), which is similar to that of the solid floor $[27,28]$. The initial cracks occurred mainly in the joints, indicating the interfaces of cast-insitu joint and precast panels are still the weaker section. Besides that, it is suggested to improve the bond performance of concrete at the joint and increase the roughness of concrete at the joint.

3.2. Load-Deflection Relationship. The load-deflection curve of the innovative floor system is presented in Figure 11(a), where the deflection is obtained from the D1 displacement transducer, and the area load is from the accumulated mass bags. Other displacement transducers present a similar increase trend. Figure 11(b) shows the deflection of displacement transducers along the ribbed beam, which contains the logged data along the cast-in-situ concrete joint.

It can be found that the innovative floor system basically meets the requirements of engineering application. Under the area load of $12.84 \mathrm{kN} / \mathrm{m}^{2}$, the maximum deflection of the floor is $15.75 \mathrm{~mm}$, which meets the deflection limit $L / 300$ according to GB 50010-2010.

3.3. Stress Distribution. The stress distribution of the bottom surface of the concrete slab is illustrated in Figure 12(a). It is found that the compressive strains on the top surface of the concrete slab are all less than $800 \mu \varepsilon$, within elastic range. Part of the tensile strains exceeded the elastic limit of $300 \mu \varepsilon$, resulting in the crack in the bottom surface of the concrete slab. The strain increased with the area load. The strain gauges were mainly arranged in the steel rods of the bottom layer, of which the maximum strain is shown in Figure 12(b). The steel rods in the middle position approximately reached the softening stage, which verifies the rational reinforcement ratio of the design.

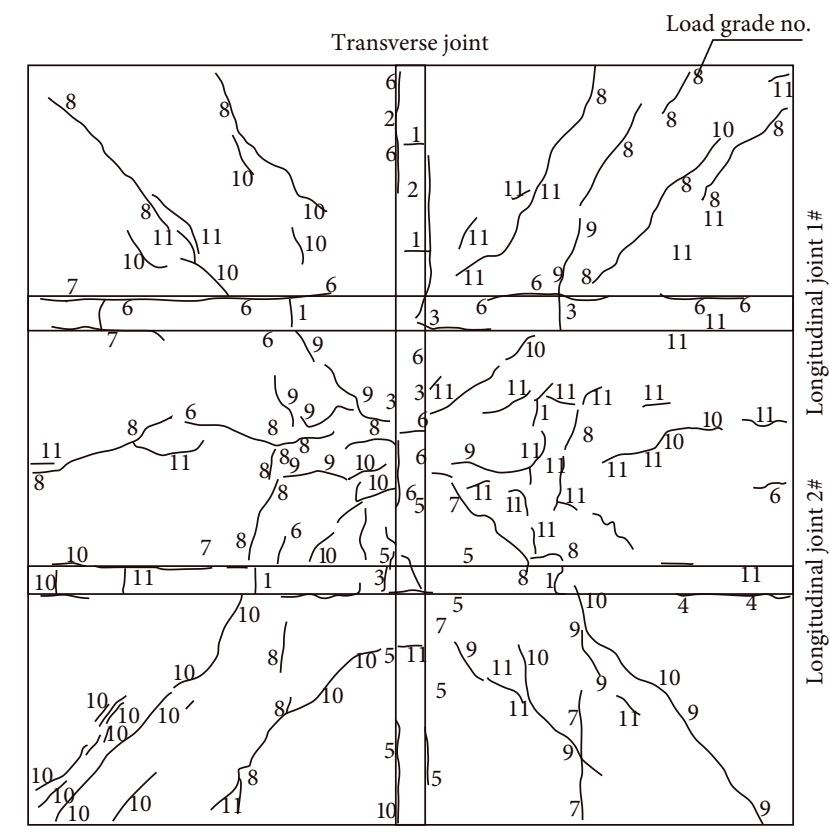

Figure 10: The cracks on the bottom surface of the slab.

\section{Comparison of the Load-Deflection Relationship with Existing Methods}

Two different calculation methods according to JGJ/T 2682012 [29], i.e., analogue cross beam method and analogue slab method, were used for both cast-in-situ slab and assembled slab. By simplifying the hollow slab into beams or thinner slab through specific principles, the maximum deflection under the design load could be calculated. The innovative floor system has no related research. Even though the corresponding limit conditions should be met when using these formulas to calculate the bearing capacity, there are still many reasonable hypotheses and empirical relationships regarding the load-carrying capacity that is worth consulting. In this section, the feasibility of the existing 

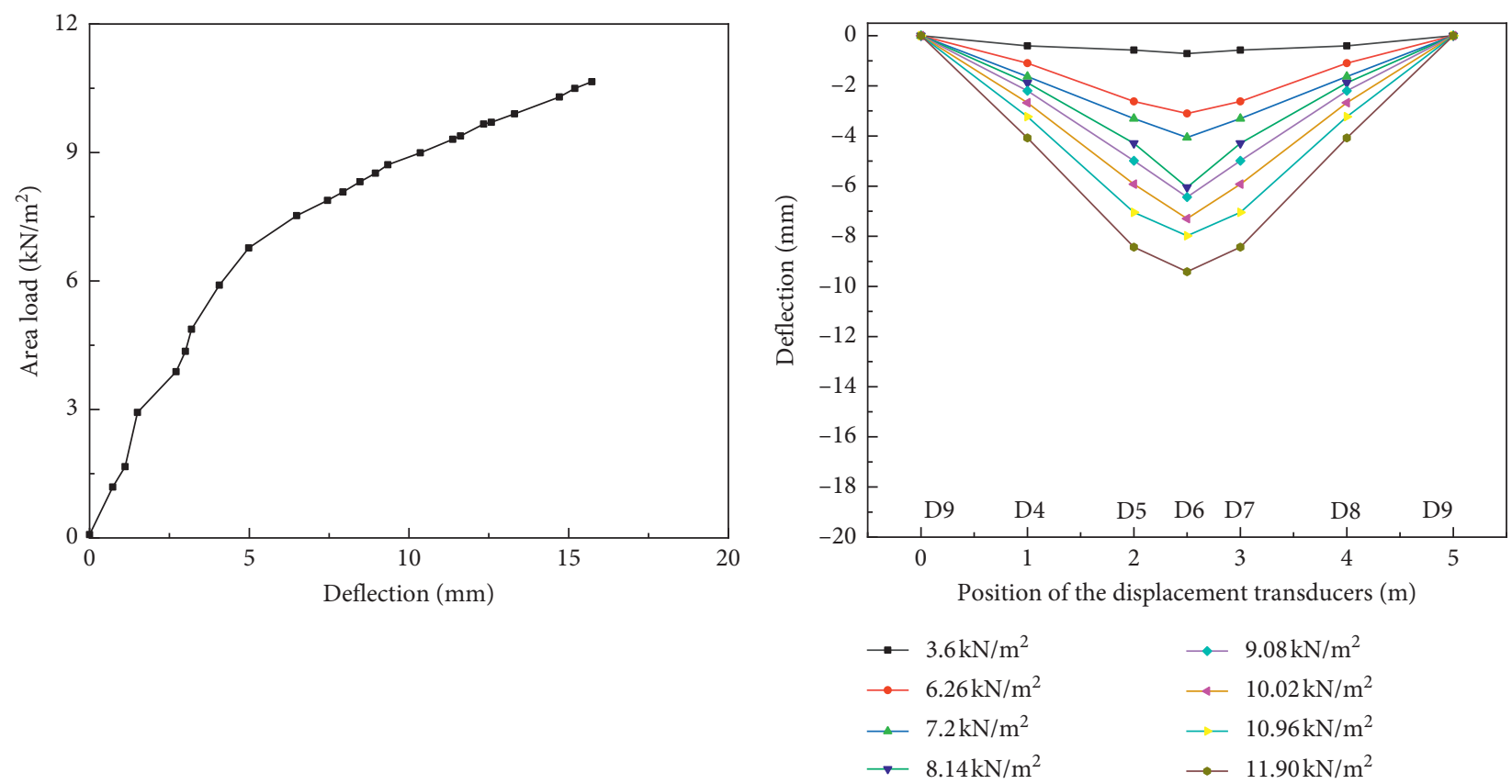

(a)

(b)

FIGURE 11: Experimental results: (a) load-deflection relationship of D1; (b) deflection along the ribbed beam under different area loads.

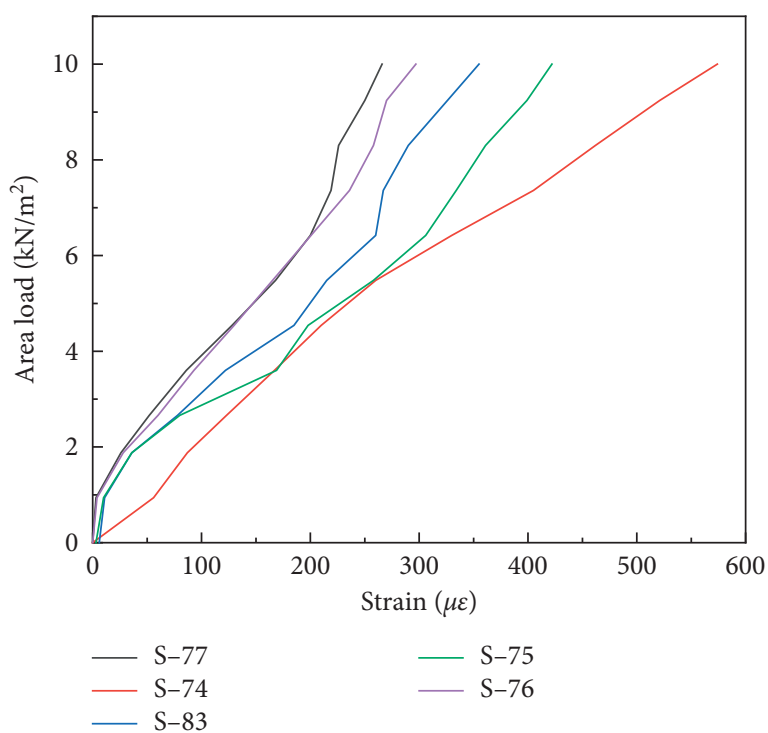

(a)

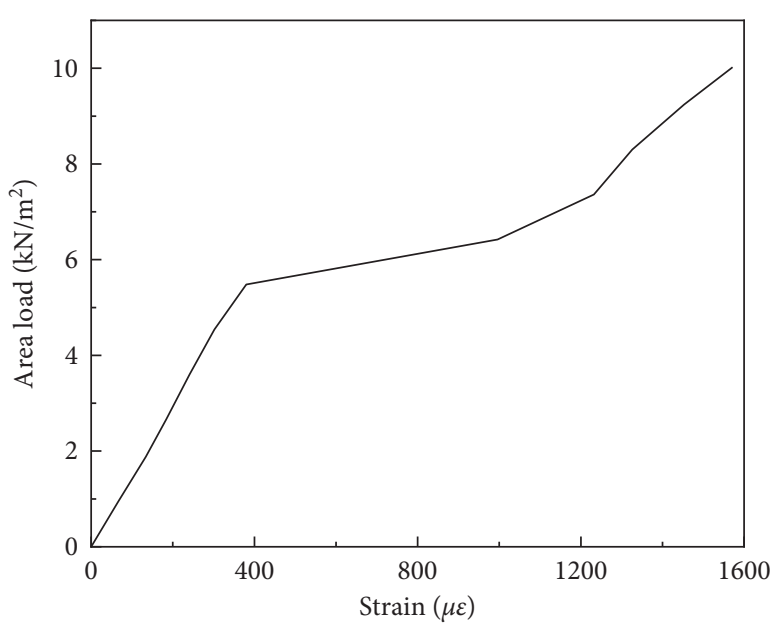

$-\mathrm{S}-27$ bottom layer.

designed methods was compared based on the experimental results.

4.1. Introduction of Existing Design Methods. Equations (2) and (3) present the calculation method for the analogue cross beam method (Figure 13) and analogue slab method (Figure 14), respectively. For the analogue cross beam method, the continuous slab is simulated by some scattered beams (the number should be larger than 5) with the same span. The sizes of the analogue cross beam are calculated with the principles that (1) the transformed beams share the same bending stiffness with the hollow slab and (2) the heights of the slab and beam remain identical; thus, the width can be calculated as follows:

$$
b_{b}=\frac{I}{I_{0}} b_{0}
$$

where $b_{b}$ is the width of the analogue cross beam, the hollow slab is divided into serval average slab strips, $b_{0}$ represents the width of the hollow slab strips, $I$ is the moment inertia of 


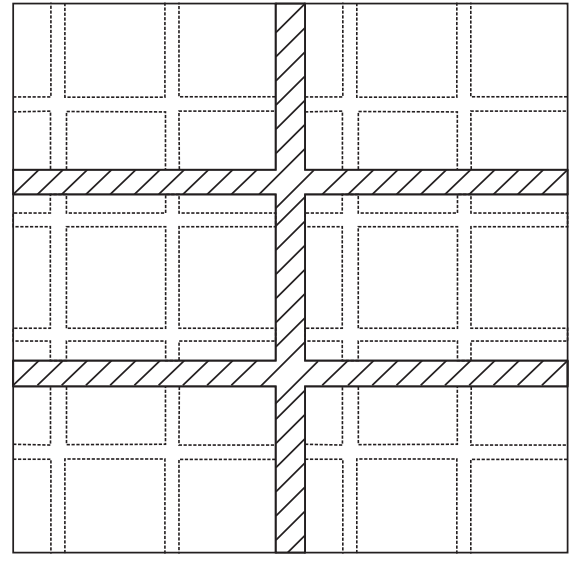

Innovated hollow concrete floor

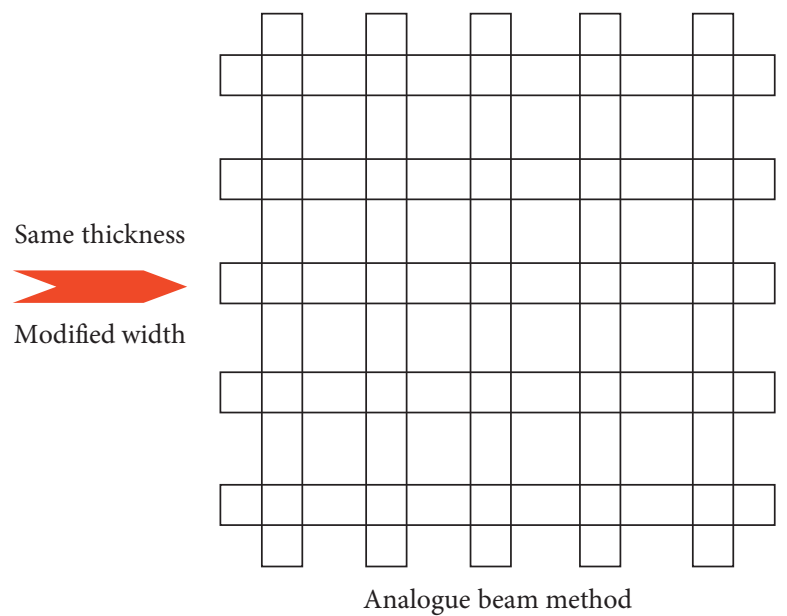

FIGURE 13: Schematic picture of analogue beam method.

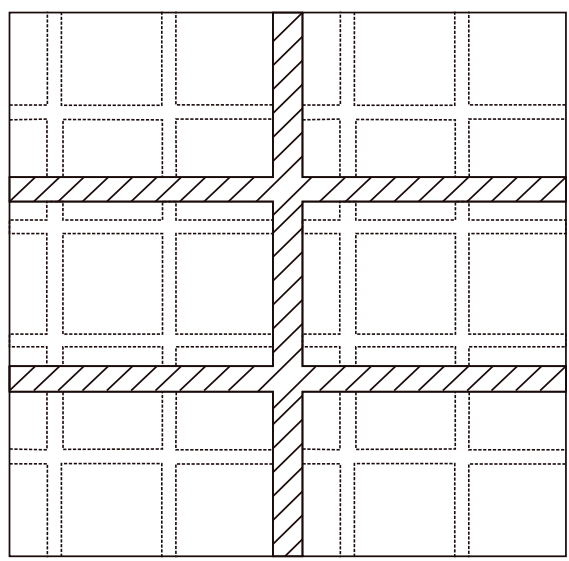

Innovated hollow concrete floor

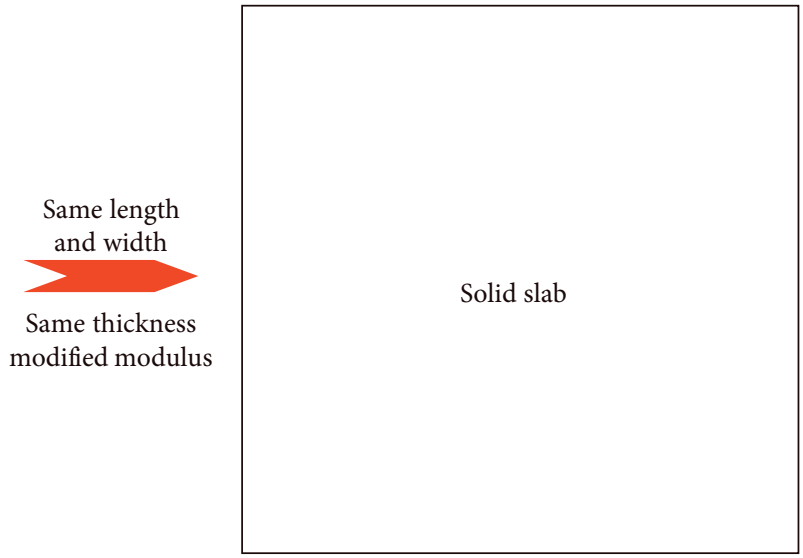

Analogue slab method

FIGURE 14: Schematic picture of analogue slab method.

the analogue cross beam, and $I_{0}$ stands for the moment inertia of the hollow slab.

For the analogue slab method, the hollow concrete slab is simulated with a solid slab of the same thickness and rectified modulus of concrete. When using the analogue slab method, the requirements are that (1) the distance between ribbed beams should be larger than $2 b_{0}$, and (2) if the difference of the two-way stiffness of concrete hollow floor can be ignored, it should be calculated as isotropic slab; otherwise, it needs to be calculated as an anisotropic slab. The modulus of the concrete and infills when calculated as the isotropic slab is calculated through the formulas below:

$$
E=\frac{I}{I_{0}} E_{c}
$$

where $E$ is the modified modulus of the analogue slab and $E_{0}$ is the modulus of the concrete and infills.

4.2. Discussion of Feasibility of Existing Design Methods. To simulate the nonlinear behavior of the innovated floor system, analogue beam and slab methods are all calculated in
ABAQUS, where the mechanical parameters of concrete and steel rods in Tables 1 and 2 are used. And the sizes of the calculated models are strictly identical to the calculation results presented in Table 5 .

Detailed sizes of the innovative floor system in ABAQUS are the same as those in Figure 3. As aforementioned, the foam concrete works as infills to improve the heat insulation of the floor. Thus, only the elastic modulus of the foam concrete in Table 2 is adopted to define their orthogonal characteristics in the linear elastic stage. While the behavior of concrete and steel bars in other parts turns out to be in the range of elastic-plastic, the whole life stage, i.e. elastic stage, softening stage, and strengthening stage, should be included in the strain-stress relation. Figures 15-17 illustrate the stress and strain relations of foam concrete, steel bars, and C30 concrete, respectively. The finite element model and its corresponding mesh are shown in Figure 18.

The element type of C3D8R (three-dimensional eightnode linear brick elements with reduced integration) in ABAQUS was chosen to simulate the large deformation of slab. The four corners are all hinged to simulate the boundary of the experiment. 
TABLE 5: Detailed information and simulation results of the analogue slab and beam methods.

\begin{tabular}{lccc}
\hline Calculation methods & Modified width $(\mathrm{mm})$ & Modified modulus $(\mathrm{MPa})$ & Number of beams \\
\hline Analogue cross beam method & 700 & - & 5 \\
Analogue slab method & - & 20700 & - \\
\hline
\end{tabular}

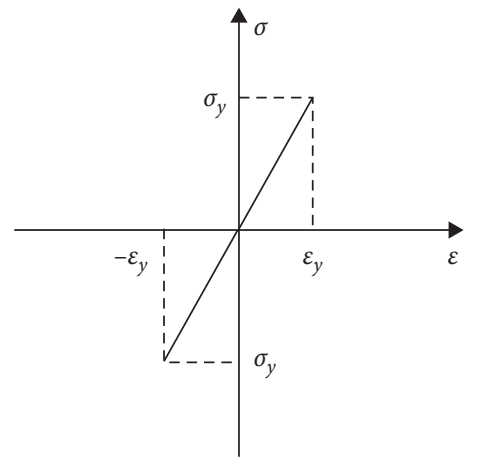

FigURE 15: Strain-stress relationship of foam concrete.
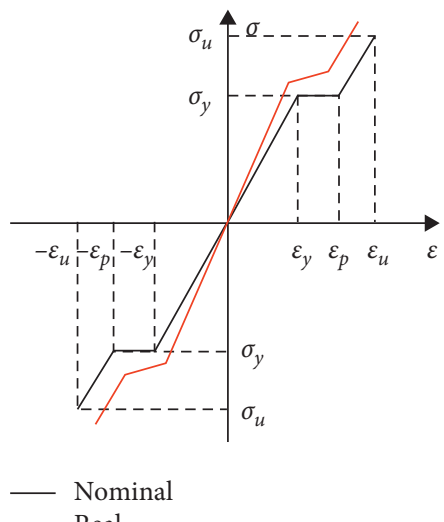

Figure 16: The strain-stress relationship of steel bars.

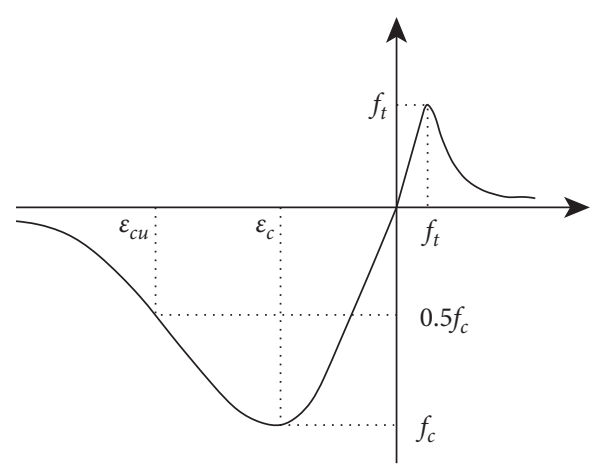

FIGURE 17: Strain-stress relationship of concrete.

The simulation results are collected in Figure 18; it is observed that the analogue cross beam method and analogue slab method present similar deformation patterns, where the maximum deflection is of little difference. The initial stiffnesses of the two analogue methods are all greater than the experimental results, which reveals that the calculation methods in JT/G 268-201 are conservative enough.
The load-deflection curves of the experimental results were compared with those of analogue cross beam and slab method, which is presented in Figure 19.

Compared with the analogue slab method, the maximum deflection in the analogue cross beam method is $11.03 \mathrm{~mm}$, which is $+3.6 \%$ greater than the experimental results. The initial stiffness of the innovative floor system is recognized as 


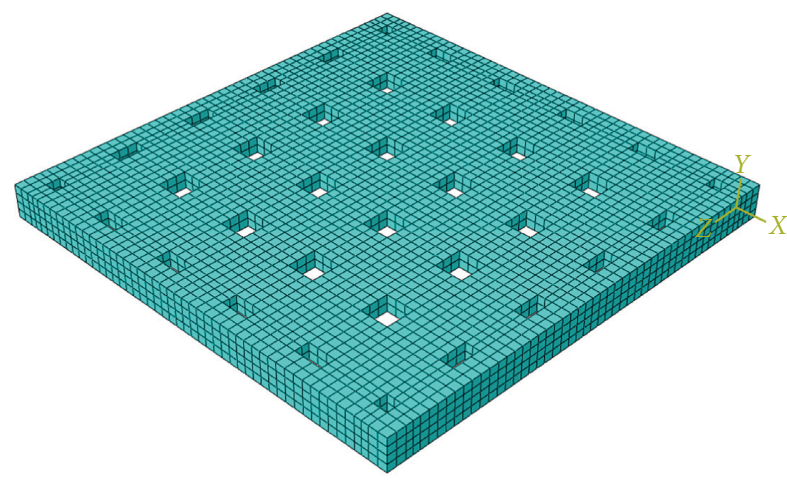

(a)
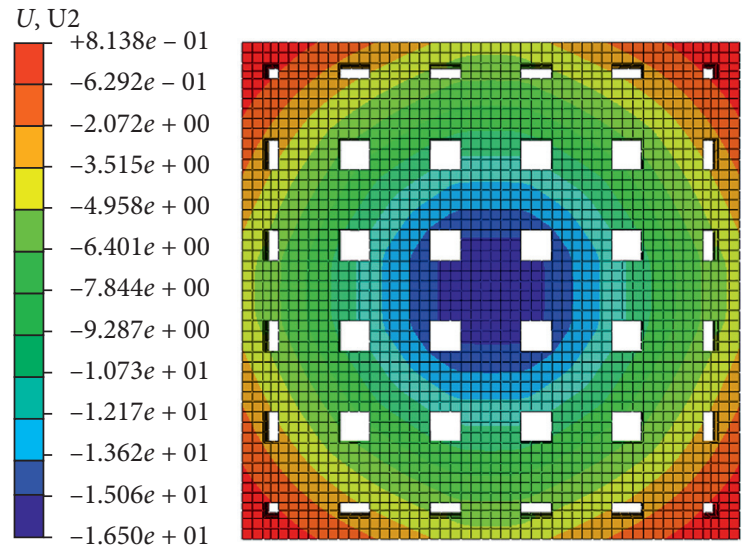

(c)

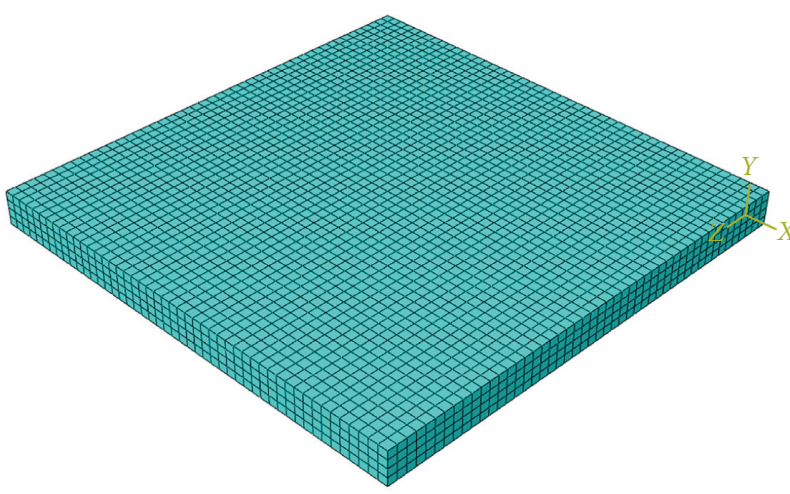

(b)

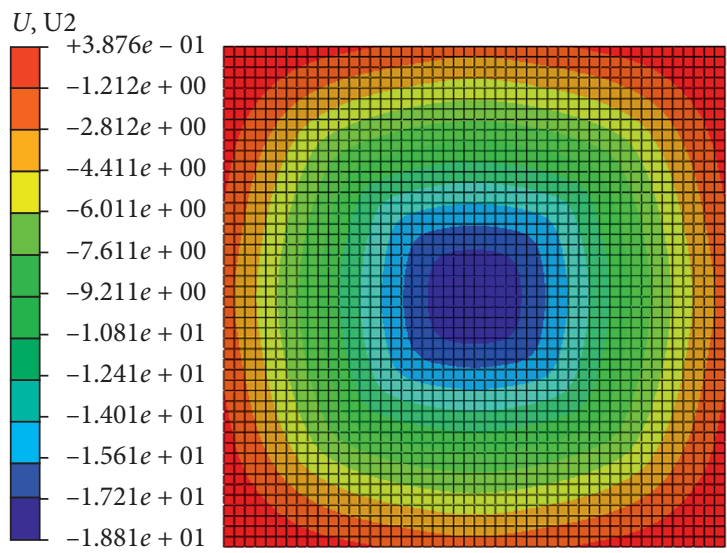

(d)

FIGURE 18: Finite element models and simulation results: (a) finite element model of analogue cross beam method; (b) finite element model of analogue slab method; (c) simulation results of the analogue cross beam method; (d) simulation results of the analogue slab method.

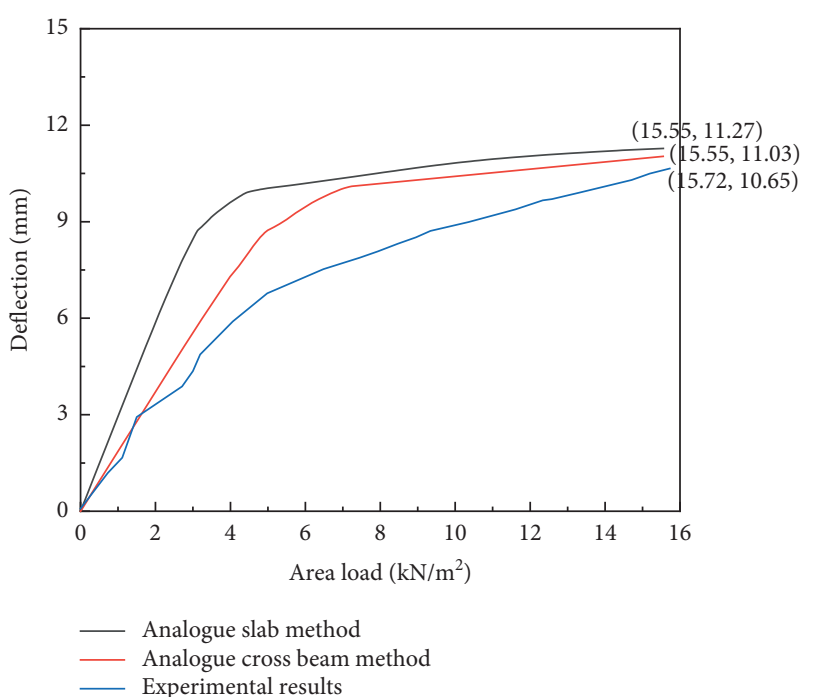

FIGURE 19: Comparison of the load-deflection relationship between the experiment and analogue methods.

the tangent of the load-deflection curve. And the absolute error of the initial stiffness between the experiment and the analogue cross section method is less than $12 \%$, which is more accurate than that of the analogue slab method. From the analysis above, the conclusion is that the analogue cross beam method according to the JT/G 268-201 is more suitable for the prediction of deflection and initial stiffness in both elastic and elastoplastic stages.

\section{Conclusions}

To test the load-carrying capacity and working mechanism of an innovative floor system, a vertical static loading test and finite element analysis of a $1 / 2$ scale floor model were conducted. Based on experimental and analytical results, the following conclusions can be drawn:

(1) The innovative floor system meets the requirements of the engineering application. Under the area load of $12.67 \mathrm{kN} / \mathrm{m}^{2}$, the maximum deflection of the floor is $15.75 \mathrm{~mm}$, which meets the deflection limit $L / 300$ under the normal service limit. Besides that, the maximum strains of steel rods and compressive concrete are both within elastic range. The experimental results all indicate that the innovative floor is safety enough in both load-carrying capacity and deflection.

(2) The development of cracks firstly occurred in the bottom of the joints, while the final distribution of cracks in the bottom of the test floor is identical to 
that of the solid floor. Thus, the following can be concluded:

(a) The stress distribution of the new floor system is similar to that of the solid two-way slab floor

(b) The joint is still the weaker section, where the bond performance and roughness of the interface between the cast-in-situ concrete and precast panels should be improved

(3) Two different kinds of simulation methods, i.e., the analogue cross beam method and the analogue slab method, were conducted to explore their efficiency in evaluating nonlinear behaviors. The analogue cross beam method is more accurate and more suitable, where the absolute error of maximum deflection is less than $5 \%$.

\section{Data Availability}

The XLSX data used to support the findings of this study are available from the corresponding author upon request.

\section{Conflicts of Interest}

The authors declare that there are no conflicts of interest regarding the publication of this paper.

\section{Acknowledgments}

The study was supported by the National Key Research and Development Project (2018YFC1100402-05) and the $\mathrm{Na}$ tional Natural Science Foundation of China (52078120) which are gratefully acknowledged.

\section{References}

[1] D. Ding, Calculation of Reinforced Concrete Floor, Press of science and technology, Shanghai, China, 1954, in Chinese.

[2] P.-C. Aitcin, "Concrete structure, properties and materials," Canadian Journal of Civil Engineering, vol. 13, no. 4, p. 499, 1986.

[3] R. B. Fleischman, C. J. Naito, J. Restrepo, R. Sause, and S. K. Ghosh, "Seismic design methodology for precast concrete diaphragms part 1: design framework," PCI Journal, vol. 50, no. 5, pp. 68-83, 2005.

[4] D. Arditi, U. Ergin, and S. Günhan, "Factors affecting the use of precast concrete systems," Journal of Architectural Engineering, vol. 6, no. 3, pp. 79-86, 2000.

[5] G. Polat, "Factors affecting the use of precast concrete systems in the United States," Journal of Construction Engineering and Management, vol. 134, no. 3, pp. 169-178, 2008.

[6] Q. Jiang, K. Zhang, Y. Feng, X. Chong, and J. Huang, "Out-ofplane flexural behavior of full precast concrete hollow core slabs with lateral joints," Structural Concrete, vol. 21, no. 5, 2020.

[7] S. C. Wang, C. S. Wang, Q. Wang, X. F. Tian, and L. Duan, "Flexural behaviors of full-scale prestressed concrete hollow slab girders with composite strengthening," Journal of Traffic and Transportation Engineering, vol. 18, no. 2, pp. 31-41, 2018.

[8] G. Fertigteil-Vertrieb, B-Z Reinforced Concrete Cellular Plate for One-Way and Two-Way Stress Directions for High Loads and Large Span, Engineering Design Brochure, Mannheim, Germany, 1965.

[9] G. Franz, Test Report Extract on A Model of The Cellular Flat Plate, South China University of Technology, Taipei, Taiwan, 1965.

[10] E. H. Hendler, "Cellular flat plate construction," Journal Proceedings, vol. 65, no. 2, pp. 81-86, 1968.

[11] K. S. Elliott, "Experimental and theoretical investigation of precast concrete hollow-cored slabs used as horizontal floor diaphragms," Magazine of Concrete Research, vol. 66, no. 12, pp. 585-602, 2014.

[12] L. Chung, S.-H. Lee, S.-H. Cho, S.-S. Woo, and K.-K. Choi, "Investigations on flexural strength and stiffness of hollow slabs," Advances in Structural Engineering, vol. 13, no. 4, pp. 591-601, 2010.

[13] E. H. Fahmy, Y. B. I. Shaheen, M. N. Abou Zeid, and H. M. Gaafar, "Ferrocement sandwich and hollow core panels for floor construction," Canadian Journal of Civil Engineering, vol. 39, no. 12, pp. 1297-1310, 2012.

[14] A. A. Yee and D. Hon, "Structural and economic benefits of precast/prestressed concrete construction," PCI Journal, vol. 46, no. 4, pp. 34-42, 2001.

[15] Y. Huang, K. Ma, H. Zhang, J. Xiao, and S. Jiang, "Study and application of Vierendeel-sandwich-plate floor framing in multistoried and tall building," Journal of Building Structures, vol. 18, no. 6, pp. 55-64, 1997.

[16] Y. Pan, "Study of load-bearing properties of PK prestressed composite slab," Master dissertation, University of Hunan, Changsha, China, 2009, in Chinese.

[17] W. Niu, "Experimental and theoretical study on waffle hollow-core composited floor," Master dissertation, University of Hunan, Changsha, China, 2009, in Chinese.

[18] R. Pang, "Research on the mechanical property and seismic design method of new type precast RC diaphragms," Master dissertation, Southeast University, Nanjing, China, in Chinese.

[19] C. Naito, L. Cao, and W. Peter, "Precast concrete double-tee connections, part 1: t," PCI Journal, vol. 54, no. 1, pp. 49-66, 2009.

[20] S. Spadea, M. Rossini, and A. Nanni, "Design analysis and experimental behavior of precast concrete double-tee girders prestressed with carbon-fiber-reinforced polymer strands," PCI Journal, vol. 63, no. 1, pp. 72-84, 2018.

[21] Q. Jiang, K. Zhang, Y. Feng et al., "Out-of-plane flexural behavior of full precast concrete hollow-core slabs with lateral joints," Structural Concrete, vol. 21, 2020.

[22] D. d. L. Araújo, M. W. R. Sales, R. P. M. Silva, C. d. F. M. Antunes, and M. d. A. Ferreira, "Shear strength of prestressed $160 \mathrm{~mm}$ deep hollow core slabs," Engineering Structures, vol. 218, Article ID 110723, 2020.

[23] National standard of the People's Republic of China, Code for Design of Concrete Structures, China Architecture \& Building Press, Beijing, China, 2015.

[24] National standard of the People's Republic of China, Metallic Materials - Tensile Testing - Part 1: Method of Test at Room Temperature, China Standard Press, Beijing, China, 2011.

[25] National standard of the People's Republic of China, Code for Seismic Design of Buildings, China Architecture \& Building Press, Beijing, China, 2016.

[26] National standard of the People's Republic of China, Standard for Test Method of concrete Structures, China Architecture \& Building Press, Beijing, China, 2012.

[27] J. Hegger, T. Roggendorf, and F. Teworte, "FE analyses of shear-loaded hollow-core slabs on different supports," 
Magazine of Concrete Research, vol. 62, no. 8, pp. 531-541, 2010.

[28] M. Abramski, A. Albert, K. Pfeffer, and J. Schnell, "Experimentelle und numerische untersuchungen zum tragverhalten von stahlbetondecken mit kugelförmigen hohlkörpern," Beton- und Stahlbetonbau, vol. 105, no. 6, pp. 349-361, 2010.

[29] National standard of the People's Republic of China, Technical Specification for Cast-In-Situ concrete Hollow Floor Structures, China Architecture \& Building Press, Beijing, China, 2012. 